\title{
Purpose and procedure
}

Evidence-Based Mental Health alerts clinicians to important advances in treatment, diagnosis, aetiology, prognosis, continuing education, economic evaluation and qualitative research in mental health. We select and summarise the highest quality original and review articles. Experts in the field comment on the clinical relevance and context of each study.

Our target audience includes psychiatrists, psychologists, nurses, social workers, occupational therapists, pharmacists and other professionals whose work may be enhanced by up to date research. Evidence-Based Mental Health is multidisciplinary. It covers studies of adults, children, older adults, people who have developed psychiatric or psychological problems as a result of trauma and people with learning disabilities, head injuries, drug and alcohol problems and personality disorders.

Evidence-Based Mental Health is published quarterly by the BMJ Publishing Group. The Editors are Professor John Geddes at the University of Oxford, Professor Shirley Reynolds at the University of East Anglia, Professor David Streiner at the Baycrest Centre for Geriatric Care and the University of Toronto and Professor Peter Szatmari at McMaster University in Canada. Dr Debbie Singh is the Managing Editor, based at Bazian Ltd, London.

\section{Selection procedure}

Evidence-Based Mental Health:

- selects the best original and review articles on the causes, diagnosis, prevention, treatment, clinical course and quality of care in mental health using pre-stated, empirically derived criteria;

- summarises these articles using structured abstracts to describe their questions, methods and results;

- adds brief commentaries by experts to place each study in its clinical context;

- disseminates these summaries to clinicians soon after the publication of the original article.

THE FOLLOWING JOURNALS ARE REGULARLY REVIEWED:

Acta Psychiatrica Scandinavica

Addiction

Age and Ageing

American Journal of Psychiatry

American Journal of Public Health

American PsychologistAnnals of Internal Medicine

Archives of General Psychiatry

Australian and New Zealand Journal of Psychiatry

British Medical Journal

Behaviour Research and Therapy

Behaviour Therapy

British Journal of Clinical Psychology

British Journal of General Practice

British Journal of Psychiatry

Canadian Journal of Psychiatry

Child Development

Clinical Psychology Review

Cochrane Library

Cognitive and Behavioral Practice

Developmental Medicine and Child Neurology

General Hospital Psychiatry

Health Psychology

International Journal of Behavioural Medicine

International Journal of Geriatric Psychiatry
Journal of the American Medical Association (JAMA)

Journal of Abnormal Child Psychology

Journal of Abnormal Psychology

Journal of Affective Disorders

Journal of Autism and Developmental Disorders

Journal of the American Academy of Child and Adolescent Psychiatry

Journal of the American Geriatrics Society

Journal of Child and Adolescent PsychopharmacologyJournal of Child

Psychology and Psychiatry and Allied Disciplines

Journal of Clinical and Experimental Neuropsychology

Journal of Clinical Psychiatry

Journal of Clinical Psychopharmacology

Journal of Consulting and Clinical Psychology

Journal of Neurology, Neurosurgery, and Psychiatry

Journal of Neuropsychiatry and Clinical Neurosciences

Journal of Psychosomatic Research

Lancet

New England Journal of Medicine

Psychiatric Services

Psychiatry Interpersonal and Biological Processes

Psychological Bulletin

Psychological Medicine

Psychology and Aging

Psychosomatic Medicine

Schizophrenia Bulletin

Social Science and Medicine

United Kingdom Health Technology Assessment Reports

We also assess journals nominated by our readers.

CRITERIA FOR SELECTING ARTICLES

Articles are considered for inclusion in Evidence-Based Mental Health if they are:

- original or review articles

- in English

- about humans

- about topics that are important to clinical practice in the field of mental health

- use analysis techniques consistent with the study design.

Studies of prevention, treatment, quality improvement and continuing education must also:

- randomly allocate participants to comparison groups

- follow up a high proportion of the original participants (eg 80\%)

- measure an outcome of known or probable clinical importance

Studies of causation (aetiology) must:

- collect data prospectively if possible

- identify a comparison group(s) for the outcome of interest

- mask outcome observers to exposure (this criterion is assumed to be met if the outcome is objective)

- include data about the relationship between modifiable exposures and clinical outcomes

Studies of diagnosis must:

- include a spectrum of participants, some, but not all of whom have the disorder of interest

- include a diagnostic (gold) standard

- include information about reliability if possible (measure of agreement among observers, for example)

- ensure each participant receives both the new test and some form of the diagnostic standard

- interpret the diagnostic standard and the new test result independently, without knowledge of the other test 
Studies of prognosis must:

- include an inception cohort of participants (first onset or assembled at a uniform point in the development of the disease), all initially free of the outcome of interest

- follow up at least $80 \%$ of the original participants

Studies of the cost-effectiveness of interventions must:

- compare alternative diagnostic or therapeutic services or quality improvement strategies

- compare activities on the basis of the outcomes produced (effectiveness) and resources consumed (costs)

- include data from real (not hypothetical) participants from studies which meet the quality criteria for other articles described above

- present results in terms of the incremental or additional costs and outcomes of one intervention over another

- include a sensitivity analysis when there is uncertainty in the estimates or imprecision in measurement

In review articles, at least one article included in the review must meet the quality criteria for treatment, diagnosis, prognosis, causation or cost effectiveness studies described above. Review articles must also:

- clearly state the clinical topic
- describe sources and methods

- explicitly state inclusion and exclusion criteria for selecting articles

Qualitative studies must meet the following criteria:

- the content must relate to how people feel or experience situations that relate to mental health care

- data collection methods must be appropriate for qualitative studies. (For example, unstructured interviews, semi-structured interviews, participant observation of people in natural settings, focus groups, review of documents or text)

\section{Summarising material}

Relevant articles which meet these criteria are summarised using a structured abstract. Articles are reviewed by experts in the field who provide commentaries describing the context of the article, methodological problems that may affect interpretation and recommendations for clinical application. If you are interested in writing an expert commentary, please contact the Managing Editor (Debbie.Singh@Bazian.com). Where possible, the author of the original article is given an opportunity to review the abstract and commentary. 